\title{
Combined therapy with cyclophosphamide and DNA preparation inhibits the tumor growth in mice
}

Ekaterina A Alyamkina ${ }^{1}$, Evgenia V Dolgova ${ }^{1}$, Anastasia S Likhacheva ${ }^{2}$, Vladimir A Rogachev², Tamara E Sebeleva², Valeriy P Nikolin², Nelly A Popova ${ }^{1,2}$, Konstantin E Orishchenko ${ }^{2}$, Dmitriy N Strunkin ${ }^{3}$, Elena R Chernykh ${ }^{4}$, Stanislav N Zagrebelniy ${ }^{1}$, Sergei S Bogachev*2 and Mikhail A Shurdov 5

Address: ${ }^{1}$ Novosibirsk State University, Novosibirsk, Russia, ${ }^{2}$ Institute of Cytology and Genetics, Siberian Branch, Russian Academy of Sciences, Novosibirsk, Russia, ${ }^{3}$ Municipal Hospital, Oncology Department, Novosibirsk, Russia, ${ }^{4}$ Institute of Clinical Immunology, Siberian Branch, Russian Academy of Medical Sciences, Novosibirsk, Russia and ${ }^{5}$ LLC Panagen, Gorno-Altaisk, Russia

Email: Ekaterina A Alyamkina -_just_smile@mail.ru; Evgenia V Dolgova -_tya_@gorodok.net;

Anastasia S Likhacheva - nastasiya_l@rambler.ru; Vladimir A Rogachev - rogachev@bionet.nsc.ru; Tamara E Sebeleva - sebeleva@bionet.nsc.ru; Valeriy P Nikolin - nikolin@gorodok.net; Nelly A Popova - nelly@bionet.nsc.ru; Konstantin E Orishchenko - keor@academ.org;

Dmitriy N Strunkin - strunkind@mail.ru; Elena R Chernykh - ct_lab@mail.ru; Stanislav N Zagrebelniy - grant@fen.nsu.ru;

Sergei S Bogachev* - labmolbiol@mail.ru; Mikhail A Shurdov - shurdov@gmail.com

* Corresponding author

Published: 14 August 2009

Genetic Vaccines and Therapy 2009, 7:12 doi:10.1186/1479-0556-7-12

This article is available from: http://www.gvt-journal.com/content/7/I//2

(c) 2009 Alyamkina et al; licensee BioMed Central Ltd.

This is an Open Access article distributed under the terms of the Creative Commons Attribution License (http://creativecommons.org/licenses/by/2.0), which permits unrestricted use, distribution, and reproduction in any medium, provided the original work is properly cited.
Received: I June 2009

Accepted: 14 August 2009

\begin{abstract}
Background: When cyclophosphamide and preparations of fragmented exogenous genomic double stranded DNA were administered in sequence, the regressive effect on the tumor was synergic: this combined treatment had a more pronounced effect than cyclophosphamide alone. Our further studies demonstrated that exogenous DNA stimulated the maturation and specific activities of dendritic cells. This suggests that cyclophosphamide, combined with DNA, leads to an immune response to the tumors that were grafted into the subjects post treatment.
\end{abstract}

Methods: Three-month old CBA/Lac mice were used in the experiments. The mice were injected with cyclosphamide (200 mkg per I kg body weight) and genomic DNA (of human, mouse or salmon sperm origin). The DNA was administered intraperitoneally or subcutaneously. After 23 to 60 days, one million tumor cells were intramuscularly grafted into the mice. In the final experiment, the mice were pre-immunized by subcutaneous injections of 20 million repeatedly thawed and frozen tumor cells. Changes in tumor growth were determined by multiplying the three perpendicular diameters (measured by caliper). Students' t-tests were used to determine the difference between tumor growth and average survival rate between the mouse groups and the controls.

Results: An analysis of varying treatments with cyclophosphamide and exogenous DNA, followed by tumor grafting, provided evidence that this combined treatment had an immunizing effect. This inhibitory effect in mice was analyzed in an experiment with the classical immunization of a tumor homogenate. The strongest inhibitory action on a transplanted graft was created through the following steps: cyclophosphamide at $200 \mathrm{mg} / \mathrm{kg}$ of body weight administered as a pretreatment; $6 \mathrm{mg}$ fragmented exogenous DNA administered over the course of 3 days; tumor homogenate grafted 10 days following the final DNA injection.

Conclusion: Fragmented exogenous DNA injected with cyclophosphamide inhibits the growth of tumors that are grafted to mice after this combined treatment. 


\section{Background}

There is considerable interest in immunomodulatory oligonucleotides (IMOs) that either contain CpG motifs or have a phosphorothioate backbone [1]. Experimental data indicated that these DNA, when administered systemically, were able to induce the adaptive immune response. This property of IMOs is widely discussed in terms of its use for cancer immunotherapy [2-6].

IMOs act as a stimulant on immunocompetent T-lymphocytes, natural killer cells, macrophages, and dendritic cells (DCs). DCs are the primary target. IMOs, as an inducer of DC immunocompetency (depending on conditions), can exert both anticancer and suppressive influences. DCs treated with specific IMOs affect the direction of differentiation in naive CD4+ CD25- T-cells $[7,8]$. There is experimental evidence indicating that the immunogenic properties of IMOs are due to their effect on the Toll-like receptors (TLRs) detected in large quantities in plasmatic DCs and macrophages [9-11]. TLR9s are the pattern-recognizing receptors that initiate the innate and adaptive immunity. Interaction of DC TLR9 with a specific IMO ligand is the first and crucial step in activating the DC's ability to induce a biological anticancer effect; subsequently, the synthesis and secretion of main cytokines and T-lymphocyte differentiation take place. When the T8+ pathway is activated, DCs efficiently present antigens (AGs) and tumor AGs to T-cytotoxic lymphocytes in order to stimulate their proliferation. This leads to the formation of an anti-tumor adaptive immune response.

The regression stimulated by this cytostatic treatment synergize with subsequent IMO injections [4]. The antitumor activities of specific nucleotides, when administered immediately after cytostatic treatments, are considerably augmented. It is imperative to strictly adhere to the administration of cytostatics (including cyclophosphamide (CP)), followed by IMOs, in order to synergize the components and increase their efficacy as a cancer treatment.

The synergy of these components could stem from the decreased number of regulatory T-lymphocytes (Tregs). This decrease suppresses the Tregs' adaptive immunity, and delays their development (in comparison to CD8+ Tlymphocytes after myelosupression under cytostatic effect). Another possible explanation for the synergistics is that cytostatics enhance the immune response to tumor AGs (thus altering their immunogenicity).

Inhibition of the Tregs antitumor response is presumably a major obstacle to the success of tumor vaccinations and immunotherapy $[4,12]$. Based on clinical trials, it may be assumed that the efficacy of antitumor IMO therapy may be boosted by a pre-inactivation of Tregs. Treatments with cytostatics at therapeutic doses kill lymphocytes of all types, irrespective of their properties. The results of many studies provide evidence that Tregs may have a greater sensitivity to cytostatics than normal T-cells [13-20]. It thus appears that chemotherapy can selectively and strongly alter Tregs, while sparing the viability of T-cytotoxic lymphocytes, which are the determinants of the high anti-tumor efficiency of this therapy $[17,21,22]$. Tumor microenvironments harbor the activity of Tregs, suppressing the immune effect on tumor cells and thus protecting the tumor from immune regression. In such a case, chemotherapy not only decreases the number of Tregs, but also abolishes their defense function [14,20,23-25]. The stripped nude tumor is rendered susceptible to the effect of the innate and adaptive immunity induced by IMOs. Tumor microenvironments actually change during sparing treatment with cytostatics. DCs become activated and form a T-cytotoxic response to the tumor (which had previously escaped immune surveillance [4]).

Our previous studies established that not only IMOs, in combination with cytostatics, had a suppressive effect on tumor development; tumor growth was also significantly inhibited by a combined treatment of $\mathrm{CP}$ and human genomic double stranded DNA (dsDNA) fragmented to 200-6000 bp [26]. This combined treatment was much more effective than treatment with $\mathrm{CP}$ alone.

When exogenous DNA was used as a leukostimulator after CP-induced myelosuppression, tumors that were grafted post treatment were reduced. Combined treatment of CP and DNA was successful at strongly suppressing growth of tumor grafted before the treatment [26] and after it [this study].

Our further studies demonstrated that fragmented exogenous genomic dsDNA stimulates the maturation of DCs and activates their specific activity [unpublished data]. We suggest that treatment with CP and exogenous DNA leads to activation of the immune system.

In recent experiments, we tested regimens of $\mathrm{CP}$ and fragmented genomic DNA administration. We also followed the timeline of change in tumors that were grafted to mice (pre-treated or not with AGs). CP injections, in combination with subsequent fragmented genomic dsDNA treatments, provided evidence that this co-therapy had a pronounced antitumor effect on tumor grafts.

\section{Methods \\ Animals}

Three-month old CBA/Lac mice that were bred at the animal facility of the Institute of Cytology and Genetics (the Siberian Branch of the Russian Academy of Sciences) were used in experiments. Mice in groups of 10 were housed in 
plastic cages. They had free access to food and water. All experiments were performed in accordance with protocols approved by the Animal Care and Use Committee of the Institute of Cytology and Genetics.

\section{Preparations of DNA}

Human DNA preparations were isolated from the placentas of healthy women using a phenol-free method; this made it possible to obtain a genome that preserves the fragments that are in vivo associated with the nuclear matrix (scaffold) proteins. The DNA preparation did not contain histones and polysaccharides; it was endotoxinfree. Mouse DNA was isolated from a mixture of tissues (thymus, liver, kidneys, spleen) and salmon sperm DNA was isolated from salmon sperm. DNA was fragmented in an ultrasonic disintegrator at a frequency of $22 \mathrm{kHz}$, to obtain a mixture of DNA fragments with a size of 200 to $6000 \mathrm{bp}$. DNA preparations were dissolved in saline and stored at a temperature of $-20^{\circ} \mathrm{C}$.

\section{Mouse treatment regimens}

The mouse treatment regimens are schematically represented in the figures that can be found in the Results section. CP (Veropharm, Russia) that was dissolved in saline was injected intraperitoneally (i.p.). Mice received either one CP injection (experiments 3-6) or two (experiments 1 and 2) on a daily interval. The total CP dose did not exceed $200 \mathrm{mg}$ per $1 \mathrm{~kg}$ of body weight. This was followed by 3-12-fold administrations of $1 \mathrm{mkg}-2 \mathrm{mg}$ DNA preparations (of human, mouse or salmon sperm origin) that were injected i.p. or subcutaneously (s.c.) into the backs of mice for 1-3 days. In experiments 1 and 2, mice were additionally i.p. injected with $1 \mathrm{mg}$ DNA $30 \mathrm{~min}$ prior to the $\mathrm{CP}$ injection, and they received $0.5 \mathrm{mg}$ DNA during the interval between the two CP injections (30-40 min after the first CP dose). The control groups in experiments 1 and 5 were treated with saline instead of DNA or CP. The control groups in experiment 1 were mice that received either $\mathrm{CP}$ alone or DNA alone according to the regimen given in Fig. 1. The control mice in experiment 5 were given CP $200 \mathrm{mg} / \mathrm{kg}$ two months before the tumors were grafted. Tumor cells were grafted $23-60$ days after the last DNA administration. Groups of 6-10 mice were used for each experiment.

\section{Tumor models}

We used Krebs-2 and lymphosarcoma (LS) tumors. The transplantable mouse LS was induced by V.I. Kaledin (Institute of Cytology and Genetics, Siberian Branch of the Russian Academy of Sciences, Novosibirsk, Russia) in CBA mice using nitrosomethylurea, transformed into an ascitic form, and maintained in this line. LSs are highly sensitive to the apoptosis induced by $\mathrm{CP}$ and several other alkylating agents. The Krebs- 2 tumors were initially
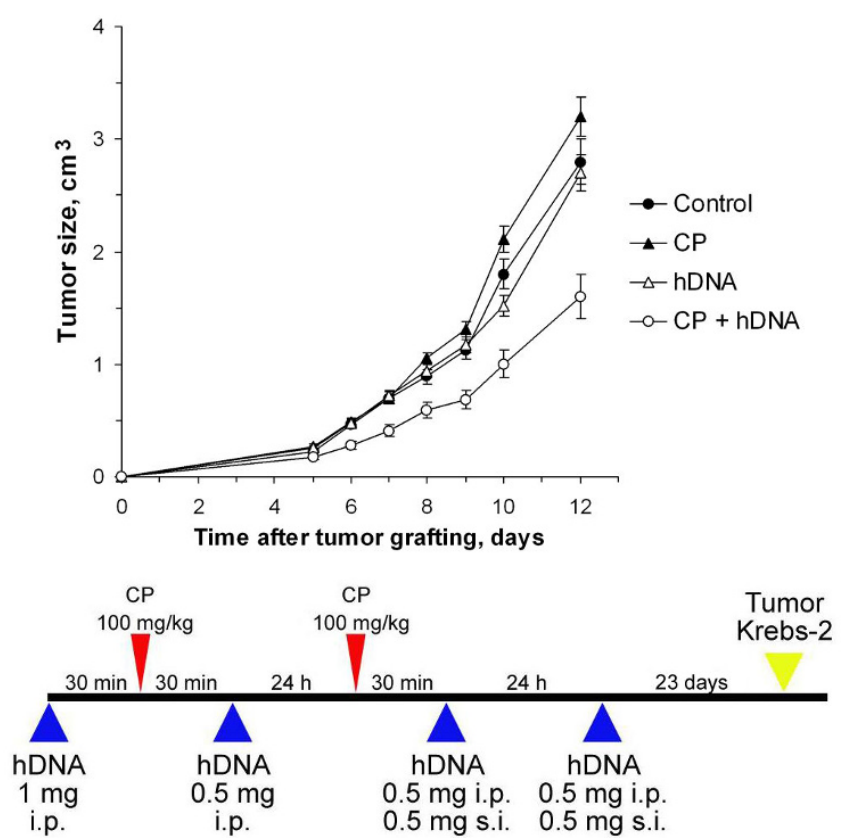

\section{Figure I}

Tumor growth (mean \pm SEM) in mice treated with CP and human DNA, comparing the regimen shown below with the control $(n=10)$. Mice received two $C P$ injections (I00 mg per I kg body weight) at a daily interval; 0.5-I mg human DNA was administered i.p. or s.c. to the mice. The control group was injected with saline. The additional control groups received either CP alone or DNA alone according to the regimen. Krebs- 2 tumor cells were grafted i.m. 23 days after the last DNA administration.

derived from mammary gland adenocarcinomas; they are mouse nonspecific and do not spread by metastases.

Tumor cells $\left(1 \times 10^{6}\right)$ were grafted intramuscularly (i.m.) into the right hind thigh of the mice. Changes in tumor growth $\left(\mathrm{cm}^{3}\right)$ were determined by multiplying the three perpendicular diameters (measured by caliper). These measurements were done 8-17 days after grafting.

\section{Immunization experiment}

In experiment 6, 10 days after the mice that were injected with $\mathrm{CP}$ and human DNA were preimmunized with tumor AGs (by s.c. injection into the dorsal back of $20 \times$ $10^{6}$ repeatedly thawed-frozen Krebs- 2 tumor cells), $1 \times$ $10^{6}$ Krebs- 2 tumor cells were grafted i.m. into the right hind thigh of the mice. In this experiment, there were two additional control groups; one was immunized only, and the other was immunized after the CP injection.

\section{Statistical analysis}

Students' t-tests were used to determine the significance of the differences in tumor growth, and average survival 
between the mouse groups and the controls. All results were expressed as mean \pm SEM.

\section{Results}

Suppression of growth of experimental tumors in regimens of CP injection and exogenous dsDNA administration

We estimated the co-treatment effect of cytostatic CP, combined with a preparation of exogenous fragmented dsDNA, on the growth of experimental tumors in mice. At the early phase of the experiment, we chose the parameters for CP injections, exogenous DNA administrations, and tumor grafting with the following considerations.

The activating effect of exogenous DNA on the immune system was estimated first. For this reason, all treatments were done prior to tumor grafting. Moreover, we had established that the administration of exogenous dsDNA, 30-60 min before or after the CP injection, had no statistically significant effect on tumor growth suppression [26]. The retardation of the grafted tumor growth became conspicuous when the interval between DNA administration and CP injection was long (1-3 days after CP injection). Several administrations of exogenous dsDNA for 13 days after CP injections most efficiently suppressed tumor growth [26].

With the above parameters, we designed experiments for immune system activation in treated mice. The design included CP injections, administrations of exogenous DNA preparation and tumor grafting after different time intervals.

\section{Estimation of the effect of regimens of CP plus exogenous fragmented dsDNA on tumor growth}

We proceeded to examine the effect of $\mathrm{CP}$ injections or fragmented human dsDNA administrations prior to grafting Krebs-2 tumors (Experiment 1). As shown in Fig. 1, the effect of only CP or DNA on the tumor was statistically insignificant $(\mathrm{p}>0.05, \mathrm{n}=10)$.

In our further experiments, we used versions of CP injections combined with administrations of fragmented exogenous DNA. Fig. 2 presents the three regimens for cytostatic injections and administrations of exogenous DNA (Experiment 2). The strongest suppressive effect on the grafted Krebs- 2 tumor was created by Regimen 1 ( $\mathrm{p}<$ $0.001, \mathrm{n}=10$ ): CP was injected two times in combination with DNA (after defined intervals), and tumor were grafted 3 weeks - 1.5 months (the experiment was replicated several times) after the last DNA administration. The treatment protocol followed in Regimen 2 differed from Regimen 1 in that the mice received four additional exogenous DNA injections after the tumor grafting; this completely abolished the suppressive effect of the Regimen 1 therapy and induced the progression of the graft.
We believe that the number and function of Tregs immune suppressors recovered by the time we started to repeatedly administer exogenous DNA. Injected exogenous DNA had already driven the adaptive response toward the Tregs phenotype; this led to suppression of the initially activated immune response and tumor progression.

Four administrations of exogenous DNA preparations according to Regimen 3 (after the tumor grafting only) had a weaker effect than Regimen 1 ; however, they had a significant ( $\mathrm{p}<0.05, \mathrm{n}=10$ ) effect on Krebs-2 tumor growth in comparison with the controls.

18-30 h after systemic CP injections, interstrand crosslinks begin to repair from start to finish. These cross links are a result of human fragmented DNA presumably integrating extensively into the genome of the experimental mice. This integration was lethal for most mice [27]. To estimate how this effect may concern a synergic cooperation of the two agents, we performed Experiment 3 using a new regimen for combined treatment with cytostatic and DNA (Fig. 3). Mice received human DNA preparations every hour for $12 \mathrm{~h}$ after CP injections (Regimen 4 ) and hourly for $6 \mathrm{~h}, 13-18,19-24,25-30$, and 31-36 h after CP injections ( 6 mice per group).

It was found that survival significantly improved ( $\mathrm{p}<$ $0.05, \mathrm{n}=6$ ) in groups 1 and 5 (mice that were treated with DNA1-13 and 31-36 $\mathrm{h}$ after the CP injection) compared with those of the control group (Table 1). It was also found that survival of group $4(25-30 \mathrm{~h})$ was insignificantly shorter $(\mathrm{p}>0.05, \mathrm{n}=6$ : by $12 \%)$ than the control group. We believe that the reduced survival rate after the treatments during this interval was due to the extensive integration of exogenous DNA fragments into the genomes of treated mice, which uncoupled primary vital systems and developed diseases that lead to death.

The increased survival rate of groups 1 and 5 can be explained through the timing of the repair mechanism: it did not start at the first time interval, but it was consummate at the second. Thus, exogenous DNA could not integrate, and DNA stimulated DCs and an increased immune response caused a statistically significant increase $(\mathrm{p}<$ $0.05, \mathrm{n}=6$ ) in survival.

Regimen 4 was not substantially different from the general outline described in the beginning of the section. Its set of experiments resulted with the persistent suppression of grafted tumors. Its efficiency is comparable to that obtained with Regimen 1.

Using Regimen 4, we estimated the inhibitory effect of single and multiple hourly administrations of exogenous 

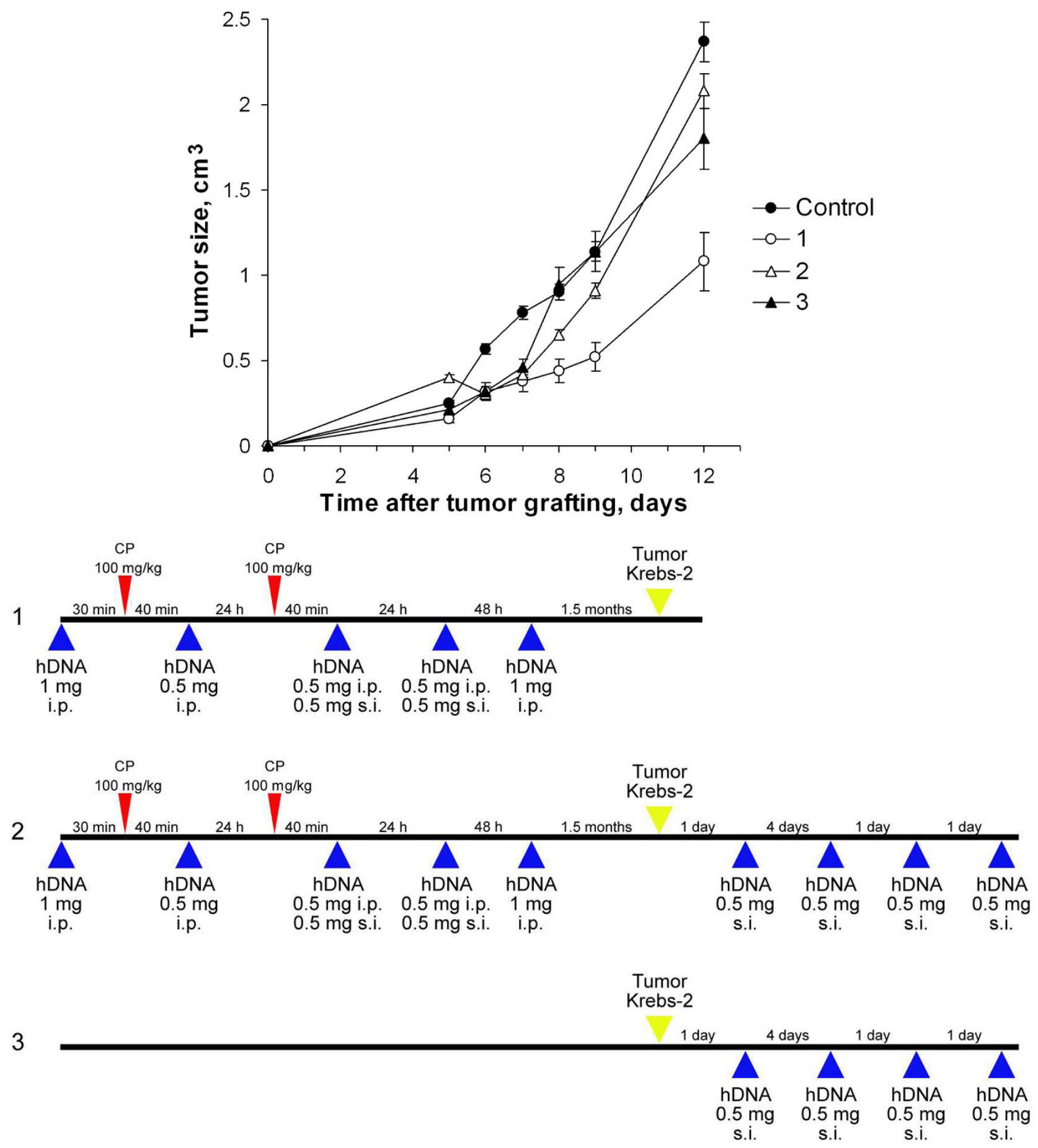

\section{Figure 2}

Tumor growth (mean \pm SEM) in mice treated with CP and human DNA, comparing the regimen shown below with the control $(\mathbf{n}=10)$. Mice received two CP injections ( $100 \mathrm{mg}$ per I $\mathrm{kg}$ body weight) on a daily interval; $0.5-\mathrm{I} \mathrm{mg}$ human DNA were administered i.p. or s.c. to the mice. The control group was injected with saline. Krebs-2 tumor cells were grafted i.m. I.5 month after the last DNA administration. The other group (2) received four human DNA s.c. injections after the tumor grafting. And the last group (3) didn't received CP but only four administrations of exogenous DNA preparations after the tumor grafting. 

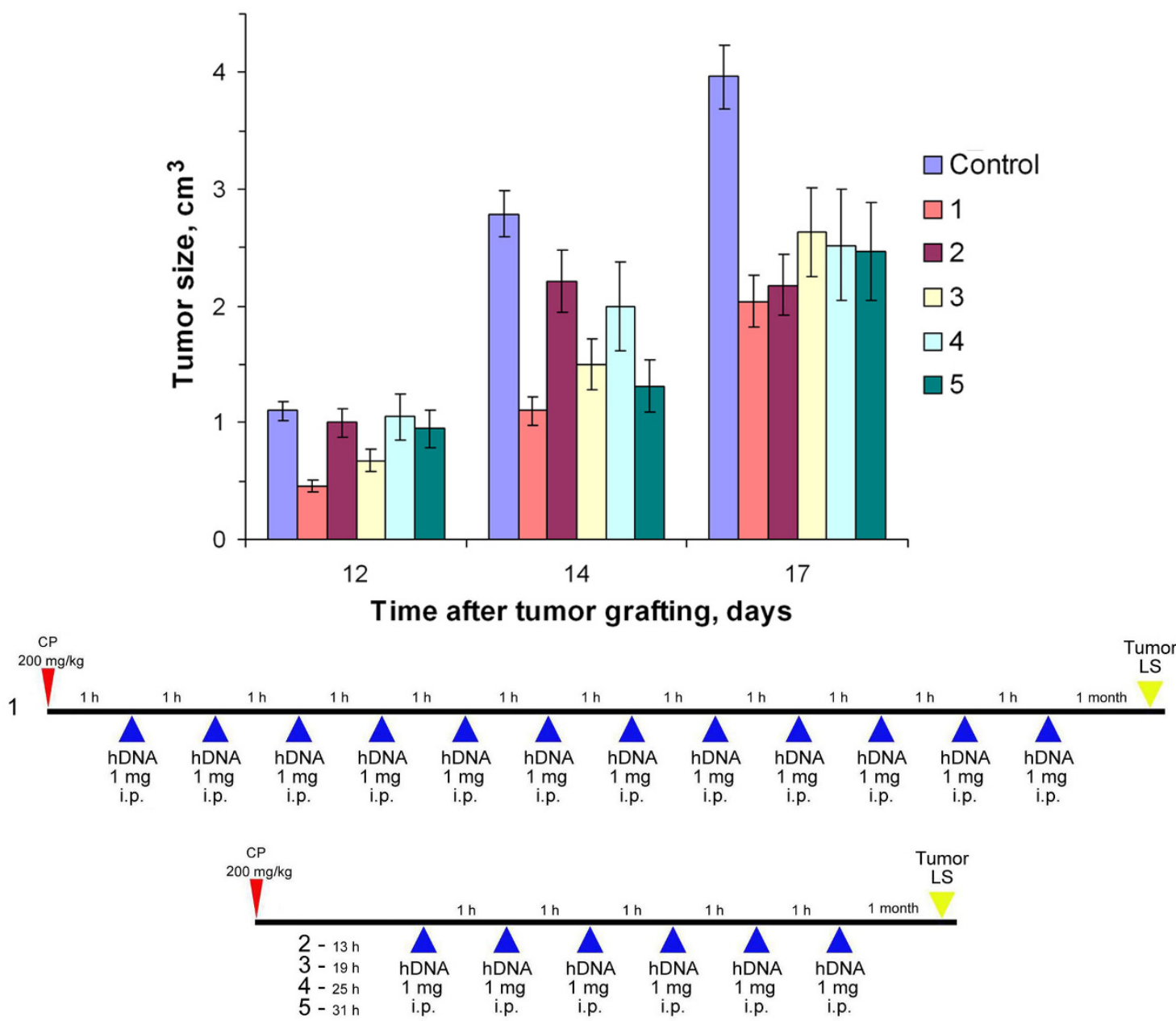

\section{Figure 3}

Tumor growth (mean \pm SEM) in mice treated with CP and human DNA, comparing the regimens shown below with the control $(\mathbf{n}=\mathbf{6})$. Mice received CP injections $(200 \mathrm{mg}$ per I kg body weight); I (I), I3 (2), I9 (3), 25 (4), 3 I (5) h after I mg DNA was administered i.p. every hour, I 2 (I) or 6 (2-5) times. The control group was injected with saline. LS tumor cells were grafted i.m. I month after the last DNA administration.

DNA preparations for $12 \mathrm{~h}$ after the $\mathrm{CP}$ injection (data not shown). Evidence indicated that multiple administrations of DNA preparation $0-12 \mathrm{~h}$ after the CP injection led to suppressed tumor growth. Vice versa, a single exogenous DNA administration at different times for $1-12 \mathrm{~h}$ after the $\mathrm{CP}$ injection had no suppressive effect on the growth of a grafted Krebs-2 tumor.

Analysis of a dose-dependent suppressive effect (with dsDNA preparations) provided evidence that $10-100 \mathrm{mkg}$ was an efficient dose $(\mathrm{p}<0.005, \mathrm{n}=7)$ to suppress tumor growth, while $1 \mathrm{mkg}$ per mouse insignificantly suppressed tumor growth ( $\mathrm{p}>0.05, \mathrm{n}=7$ ) (Experiment 4, Fig. 4). Overall, the preparations increased the average mice survival insignificantly $(\mathrm{p}>0.05, \mathrm{n}=7$ ) (Table 2$)$. The DNA used in this experiment was allogenic, obtained from CBA mice.

\section{Estimation of the effect of exogenous DNA from different organisms on tumor growth on the background of CP therapy}

In Experiment 5, we analyzed the effect of exogenous DNA based on its species origin (Fig. 5). Regimen 4 was chosen for obtaining estimates. The results showed that human xenogenic DNA combined with CP injections had the strongest statistically significant suppressive effect $(\mathrm{p}<$ $0.005, \mathrm{n}=6$ ) on grafted tumor development, compared to allogenic mouse DNA ( $\mathrm{p}<0.05, \mathrm{n}=6)$ and distantly related DNA derived from salmon sperm $(p<0.05, n=6)$. 
Table I: Average survival of mice in Experiment 3.

\begin{tabular}{ll}
\hline Group & Survival, days \\
\hline Control & $18.7 \pm 0.8$ \\
\hline 1 & $22.1 \pm 1.2$ \\
\hline 2 & $18.2 \pm 1.4$ \\
\hline 3 & $19.0 \pm 1.1$ \\
\hline 4 & $16.4 \pm 0.2$ \\
\hline
\end{tabular}

The values are means $\pm \operatorname{SEM}(n=6)$.

Estimation of immunization intensity for sequential treatment with cytostatic and exogenous genomic dsDNA In Experiment 6, mice were additionally immunized with a tumor cell homogenate after CP and exogenous DNA (Fig. 6). This co-treatment had the strongest suppressive effect on the grafted tumor in comparison to the control $(\mathrm{p}<0.001, \mathrm{n}=10)$. The solitary immunizations and the immunizations with $\mathrm{CP}$, without DNA, were weaker.
Comparing the volumes of Krebs-2 tumors grafted according to Regimen 1 (Experiment 2) with those immunized additionally in the interval between the last DNA administration and grafting (Experiment 6) demonstrated that immunization enhanced the suppressive effect on tumor growth (Fig. 7). The following regimen exerted the strongest inhibitory action on the graft: pre-treatment with CP at $200 \mathrm{mg} / \mathrm{kg}$ of body weight; fragmented exogenous DNA given for 3 days at a total dose of $6 \mathrm{mg}$; tumor homogenate injected 10 days after last DNA injection.

\section{Discussion}

The present results evidence that exogenous DNA administered to experimental mice in combination with the cross linked cytostatic CP has an immunizing action and suppresses growth of a tumor that is grafted after this treatment. This means that $\mathrm{CP} /$ exogenous DNA co-treatments prepare the immune system to give a rapid specific immune response when tumor AGs arise. This co-treatment activates the immune system to acquire the ability to recognize tumor AGs and respond efficiently. The results of our concomitant study disclosed that this observed property of exogenous DNA is due to activation of DC maturation and a drive of the adaptive response toward cytotoxic T-cells [unpublished data].
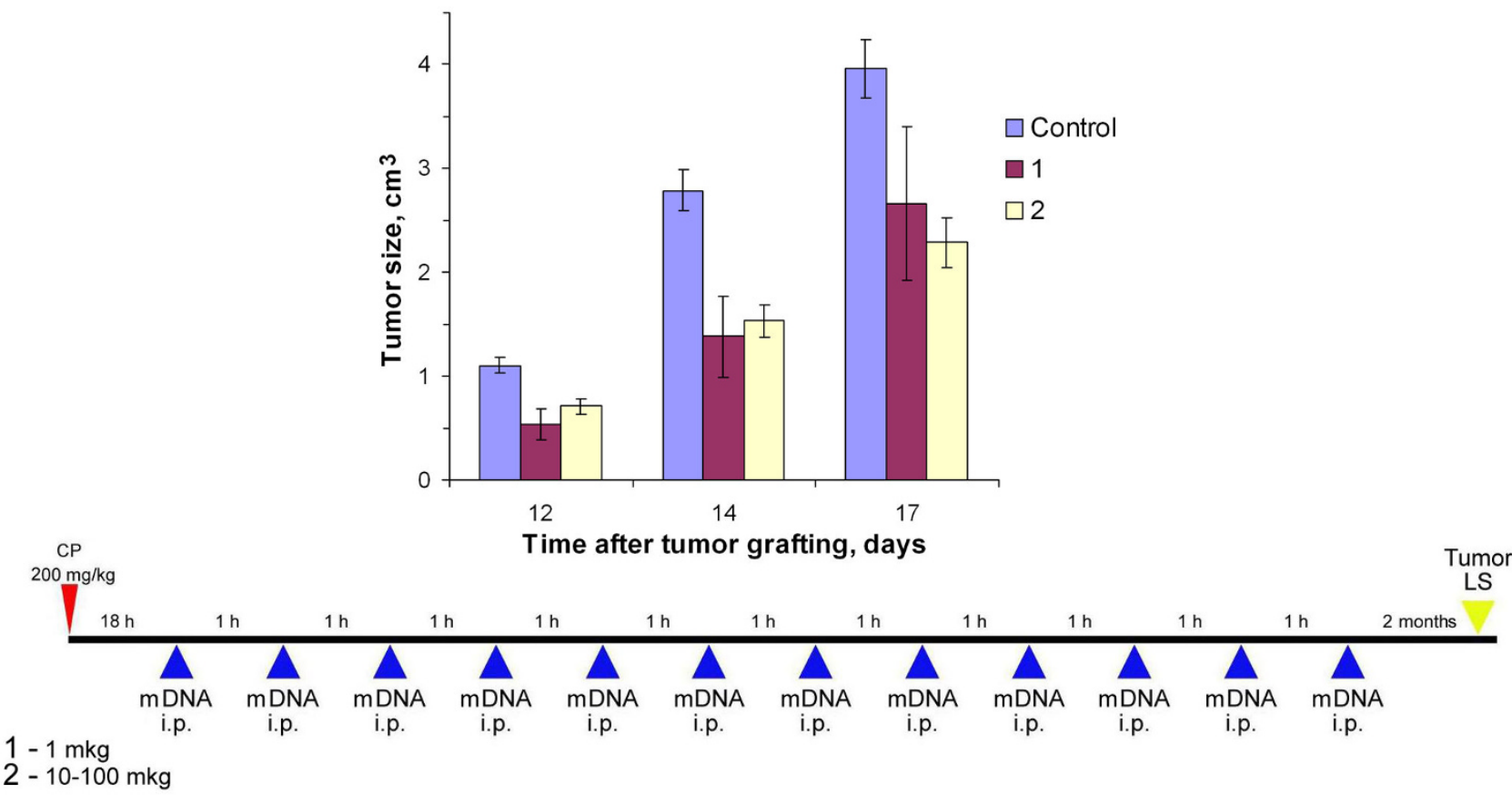

\section{Figure 4}

Tumor growth (mean \pm SEM) in mice treated with CP and different doses of mouse DNA, comparing the regimen shown below with the control $(\mathbf{n}=7)$. Mice received CP injections $(200 \mathrm{mg}$ per I $\mathrm{kg}$ body weight); I $\mathrm{h}$ afterward I mkg (I) or 10-100 mkg (2) mouse DNA was administered i.p. every hour 12 times. The control group was injected with saline. LS tumor cells were grafted i.m. 2 months after the last DNA administration. 
Table 2: Average survival of mice in Experiment 4.

\begin{tabular}{ll}
\hline Group & Survival, days \\
\hline Control & $18.7 \pm 0.8$ \\
\hline 1 & $25.0 \pm 3.4$ \\
\hline 2 & $23.1 \pm 2.0$
\end{tabular}

The values are means $\pm \operatorname{SEM}(n=7)$.

Experiments designed to elucidate the synergic suppressive effect of cytostatics and immunomodulatory DNAs (which CpG DNA with a normal sugar phosphate backbone and oligonucleotides whose backbone sugar phosphorothioate belong to) are widely discussed. To our knowledge, all studies have attributed this synergic suppressive effect to the activation of both the innate immune and (more frequently) the adaptive immune response to the spreading tumor tissue. Differentiated suppression of Tregs and CD8+ T-cytotoxic lymphocytes under the effect of cytostatic, in the case of CP and IMOs (CpG) co-ther- apy, leads to activation of the innate and adaptive immunity.

Tumors induce the rapid capture of Tregs and Tregs-produced cytokines that inhibit the adaptive immunity [2830]. CP creates and defines conditions for the differentiated suppression of T-cytotoxic and T-regulatory lymphocytes, and there exists an interval when the CD8+ Tcells: Tregs ratio becomes skewed by an order of two magnitudes in favor of T killer cells $[14,15,17,18,23,28,31$, 32]. The difference in suppression degree and recovery rate between CD8+ lymphocytes and Tregs is important to cancer therapy. This is the time when the tumor becomes detectable by the non-supressed immune system. Tumor AGs are presented on DCs, and the surviving CD8+ T-lymphocytes (those not under the effect of cytokines produced by Tregs) kill cells of the developing tumor [23].

In the experimental studies, mice received $\mathrm{CP}$ after the tumors' stable growth. Tumor cells were left to die for some days after cytostatic treatment [33]. It was thought that at this time DCs absorbed apoptotic bodies of dead

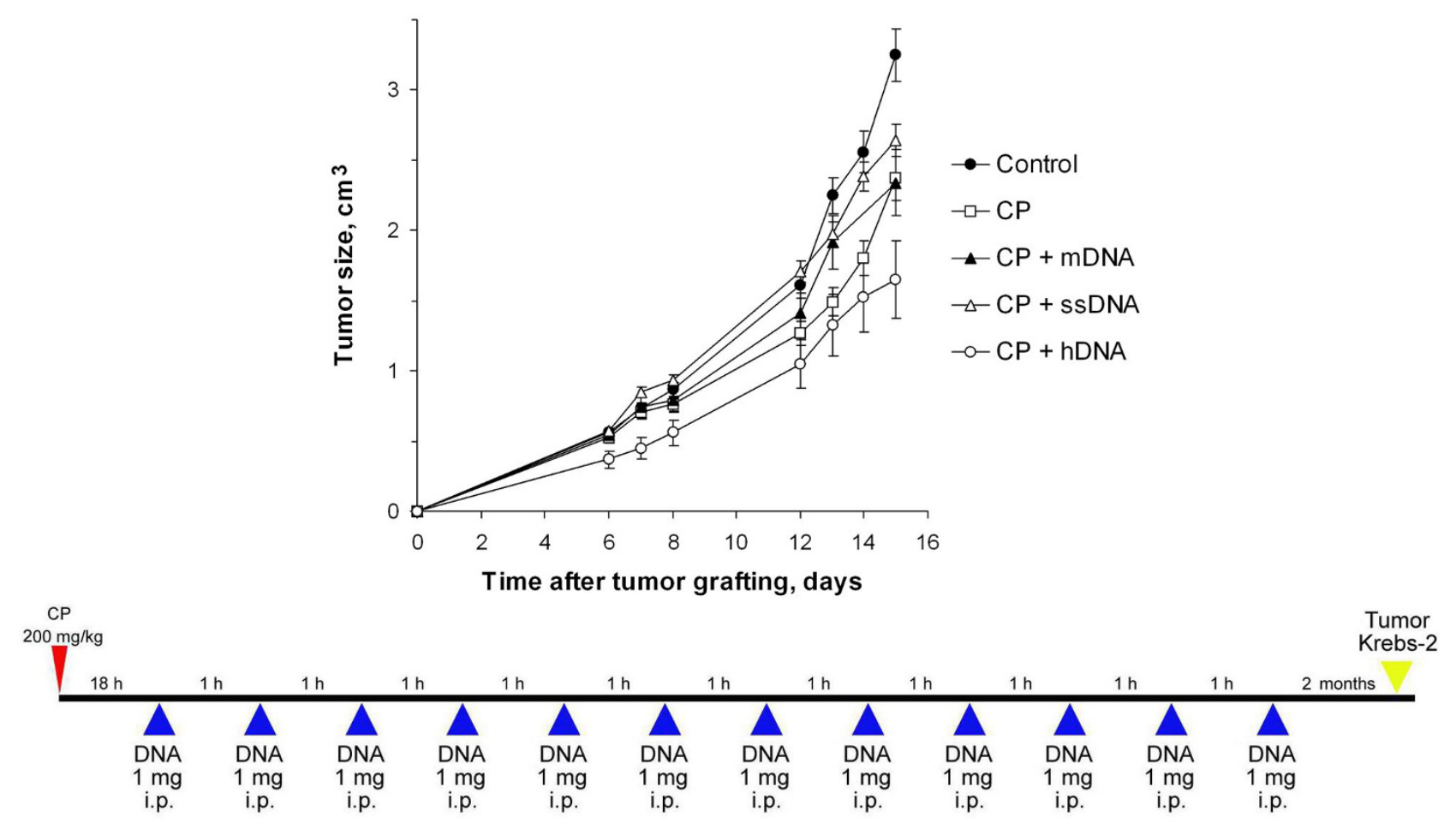

Figure 5

Tumor growth (mean \pm SEM) in mice treated with CP and DNA preparations human, mouse or salmon sperm origin, comparing the regimen shown below with the control $(\mathbf{n}=6)$. Mice received $\mathrm{CP}$ injections $(200 \mathrm{mg}$ per I $\mathrm{kg}$ body weight); I $8 \mathrm{~h}$ afterward saline ("CP") or I $\mathrm{mg}$ of genomic DNA preparations of mouse ("CP + mDNA"), salmon sperm ("CP + ssDNA") or human ("CP + hDNA") DNA were administered i.p. every hour for I 2 times. The control group was injected with saline. Krebs-2 tumor cells were grafted i.m. two months after the last DNA administration. 

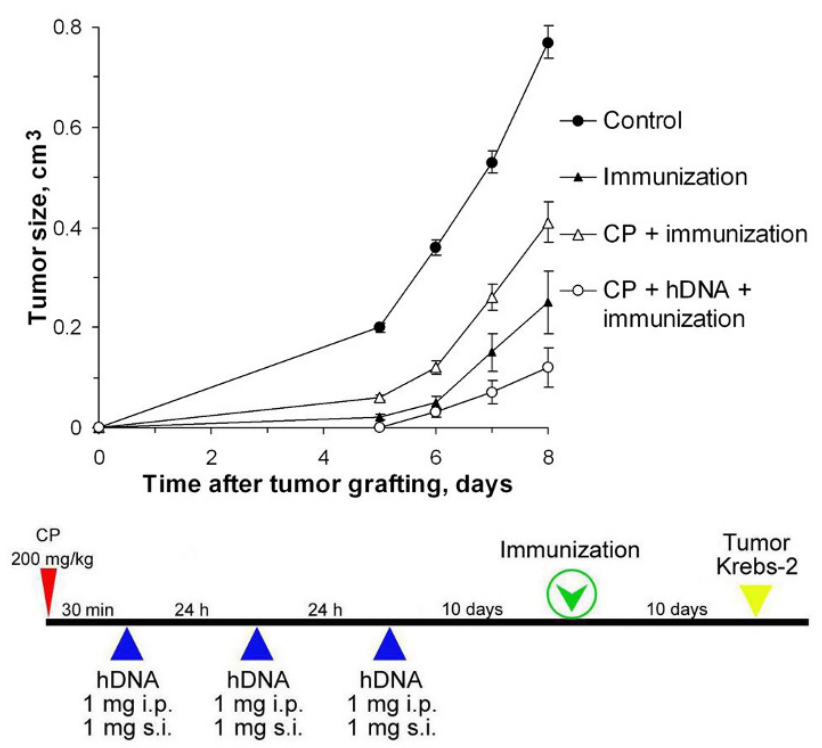

Figure 6

Tumor growth (mean \pm SEM) in mice treated with CP and human DNA, comparing the regimen shown below with the control $(n=10)$. Mice received $C P$ injections (200 mg per I kg body weight); 30 min afterward and during the consecutive two days, mice were injected with human DNA, I mg i.p. and I mg s.c.. Mice were preimmunized with tumor AGs by s.c. injection into the dorsal back of $20 \times 10^{6}$ repeatedly thawed-frozen Krebs- 2 tumor cells 10 days after the last DNA administration; 10 days after immunization I $\times 10^{6} \mathrm{Krebs}-2$ tumor cells were grafted i.m. into the right hind thigh of mice. The control group was injected with saline. There were two additional control groups; one was immunized only, and the other was immunized after the $C P$ injection.

tumor cells or DNA of another kind as a result of lysed tumor cells. The adaptive immune response was simultaneously stimulated by IMOs via the CD8+ T-cell pathway; this led to active presentation of tumor AGs and the proliferation of lymphocytes [1,14,20,23-25,33-37].

In the studies, we used a novel regimen. Mice were first treated with a combination of $\mathrm{CP}$ and a human fragmented dsDNA preparation; this was followed by tumor grafting. With this treatment, the growth of many grafted tumor cells was substantially suppressed. To reiterate, our previous study had shown that the dsDNA preparation activates DCs ex vivo and induces their maturation and allostimulatory activity [unpublished data]; it is precisely this link of the immune system that activates tumor suppression.

In the experiments, doses of CP were therapeutic standard (200 mg/kg). The results clearly showed that the suppres-

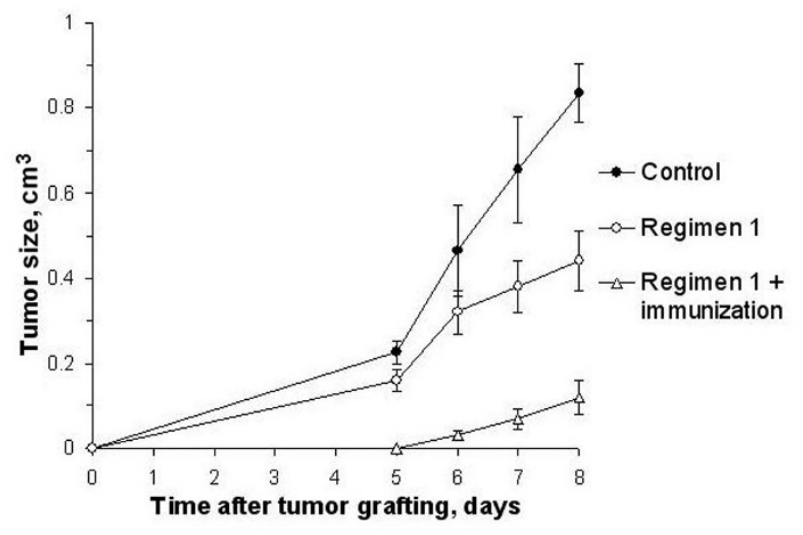

Figure 7

Tumor growth (mean \pm SEM) in mice treated according to Regimen I and additionally immunized $(\mathbf{n}=10)$. The control group was injected with saline. In Regimen I, mice received two CP injections ( $100 \mathrm{mg}$ per I kg body weight) on a daily interval; $0.5-1 \mathrm{mg}$ human DNA were administered i.p. or s.c. Krebs-2 tumor cells were grafted i.m. I.5 month after the last DNA administration. Regimen I + immunization, mice received CP injection (200 $\mathrm{mg}$ per I kg body weight); 30 min afterward and during the consecutive two days, mice were injected with human DNA, I mg i.p. and I mg s.c.. Mice were pre-immunized with Krebs-2 tumor AGs by a s.c. injection 10 days after the last DNA administration; Krebs- 2 tumor cells were grafted i.m. 10 days after immunization. Immunization enhanced the suppressive effect on tumor growth.

sive effect on tumor progression was manifested in all the experiments. This was due to activation of DCs by exogenous DNA, which in turn induced the adaptive immunity. Since CP at the applied doses completely eliminated both CD8+ T-cells and Tregs, exogenous DNA presumably activated DCs in such a way that just the T-cytotoxic adaptive (not the Treg suppressive) immune response was activated. This suggested that cytostatic and exogenous DNA combined treatments did not need a reduction in doses of CP for suppression of the two lymphocyte types; CP can be used at doses approved in modern practice; and the adaptive immune response is inducible at a defined time with exogenous dsDNA preparations.

Exogenous DNA activates the adaptive immune system 13 days after the injection of $\mathrm{CP}$, resulting in suppression of the grafted tumor. We chose to graft the tumors 1-2 months after the last administration of the exogenous DNA preparations based on our experience. There may be other time intervals used to achieve a stronger suppressive action on tumors.

With the literary data taken into consideration, there are grounds to believe that pre-treatments with CP and exog- 
enous DNA create an environment with effecter T-lymphocytes and DNA-activated DCs. This is after CPinduced myelosuppression is affected through the proliferation induction of cytotoxic, not suppressor, T-lymphocytes.

\section{Conclusion}

Injections of fragmented exogenous DNA, combined with $\mathrm{CP}$, inhibit the growth of tumors that are grafted to mice post treatment. It is assumed that this observed property of exogenous DNA is due to activation of DC maturation and a drive of the adaptive response toward cytotoxic Tcells.

\section{Competing interests}

The authors declare that they have no competing interests.

\section{Authors' contributions}

EAA carried out the mice experiments and performed the statistical analysis. EVD carried out the mice experiments and performed the statistical analysis. ASL carried out the mice experiments and drafted the manuscript. VAR participated in the design of the study. TES participated in the study design and helped with drafting the manuscript. VPN carried out the mice experiments, performed the analysis, and interpreted the data. NAP participated in the design of the study and performed the statistical analysis. KEO participated in the design of the study. DNS helped in the data interpretation. ERC performed the analysis and interpreted the data. SNZ participated in the study design and helped with the data interpretation. SSB conceived the study, participated in its design, and coordinated and drafted the manuscript. MAS participated in the study design and coordination. All authors read and approved the final manuscript.

\section{Acknowledgements}

The work was funded by federal target program "Scientific and educational manpower of innovative Russia (2009-2013)" No 2009-I.I-203-020010_009I and LLC Panagen. The authors are grateful to Anna Fadeeva for translating the manuscript from Russian to English.

\section{References}

1. Wang H, Rayburn ER, Wang W, Kandimalla ER, Agrawal S, Zhang R: Chemotherapy and chemosensitization of non-small cell lung cancer with a novel immunomodulatory oligonucleotide targeting Toll-like receptor 9. Mol Cancer Ther 2006, 5: $1585-1592$.

2. Olishevsky SV, Kozak VV, Yanish YuV, Rybalko SL, Shliakhovenko VA Immunostimulatory CpG DNA: prospects for clinical use in oncology. Oncologia 2006, 8:209-2 17. In Russian

3. Ishii KJ, Akira S: Innate immune recognition of, and regulation by, DNA. Trends Immunol 2006, 27:525-532.

4. Krieg AM: Development of TLR9 agonists for cancer therapy. | Clin Invest 2007, I I 7: I I 84- I I94.

5. Medzhitov R: Recognition of microorganisms and activation of the immune response. Nature 2007, 449:819-826.

6. Rakoff-Naum S, Medzhitov R: Role of Toll-like receptors in tissue repair and carcinogenesis. Biokhimia 2008, 73:690-698.
7. Hartmann G, Krieg AM: CpG DNA and LPS induce distinct patterns of activation in human monocytes. Gene Ther 1999, 6:893-903.

8. Pulendran B: Variegation of the immune response with dendritic cells and pathogen recognition receptors. I Immunol 2005, 174:2457-2465.

9. Otto F, Schmid P, Mackensen A, Wehr U, Seiz A, Braun M, Galanos C, Mertelsmann R, Engelhardt R: Phase II trial of intravenous endotoxin in patients with colorectal and non-small cell lung cancer. Eur J Cancer 1996, 32A: I7I2-17|8.

10. Liu YJ: IPC: professional type I interferon-producing cells and plasmacytoid dendritic cell precursors. Annu Rev Immunol 2005, 23:275-306

II. Kawai T, Akira S: Innate immune recognition of viral infection. Nat Immunol 2006, 7:131-137.

12. Zou W: Regulatory T cells, tumour immunity and immunotherapy. Nat Rev Immunol 2006, 6:295-307.

13. Carson WE 3rd, Shapiro CL, Crespin TR, Thornton LM, Andersen BL: Cellular immunity in breast cancer patients completing taxane treatment. Clin Cancer Res 2004, I 0:340I-3409.

14. Beyer M, Kochanek M, Darabi K, Popov A, Jensen M, Endl E, Knolle PA, Thomas RK, von Bergwelt-Baildon M, Debey S, Hallek M, Schultze $J \mathrm{~L}$ : Reduced frequencies and suppressive function of CD4+CD25hi regulatory $T$ cells in patients with chronic lymphocytic leukemia after therapy with fludarabine. Blood 2005 , 106:2018-2025.

15. Correale P, Cusi MG, Tsang KY, Del Vecchio MT, Marsili S, Placa ML, Intrivici C, Aquino A, Micheli L, Nencini C, Ferrari F, Giorgi G, Bonmassar E, Francini G: Chemo-immunotherapy of metastatic colorectal carcinoma with gemcitabine plus FOLFOX 4 followed by subcutaneous granulocyte macrophage colonystimulating factor and interleukin-2 induces strong immunologic and antitumor activity in metastatic colon cancer patients. J Clin Oncol 2005, 23:8950-8958.

16. Emens LA, Jaffee EM: Leveraging the activity of tumor vaccines with cytotoxic chemotherapy. Cancer Res 2005, 65:8059-8064.

17. Ercolini AM, Ladle BH, Manning EA, Pfannenstiel LW, Armstrong TD, Machiels JP, Bieler JG, Emens LA, Reilly RT, Jaffee EM: Recruitment of latent pools of high-avidity CD8(+) T cells to the antitumor immune response. J Exp Med 2005, 20I:I59I-1602.

18. Ghiringhelli F, Larmonier N, Schmitt E, Parcellier A, Cathelin D, Garrido C, Chauffert B, Solary E, Bonnotte B, Martin F: CD4+CD25+ regulatory $T$ cells suppress tumor immunity but are sensitive to cyclophosphamide which allows immunotherapy of established tumors to be curative. Eur I Immunol 2004, 34:336-344

19. Lake RA, Robinson BW: Immunotherapy and chemotherapy a practical partnership. Nat Rev Cancer 2005, 5:397-405.

20. Lutsiak ME, Semnani RT, De Pascalis R, Kashmiri SV, Schlom J, Sabzevari H: Inhibition of CD4(+)25+ T regulatory cell function implicated in enhanced immune response by low-dose cyclophosphamide. Blood 2005, 105:2862-2868.

21. Machiels JP, Reilly RT, Emens LA, Ercolini AM, Lei RY, Weintraub D, Okoye FI, Jaffee EM: Cyclophosphamide, doxorubicin, and paclitaxel enhance the antitumor immune response of granulocyte/macrophage-colony stimulating factor-secreting wholecell vaccines in HER-2/neu tolerized mice. Cancer Res 200I, 6I:3689-3697.

22. Chu Y, Wang LX, Yang G, Ross HJ, Urba WJ, Prell R, Jooss K, Xiong $S$, Hu HM: Efficacy of GM-CSF-producing tumor vaccine after docetaxel chemotherapy in mice bearing established Lewis lung carcinoma. J Immunother 2006, 29:367-380.

23. Motoyoshi Y, Kaminoda K, Saitoh O, Hamasaki K, Nakao K, Ishii N, Nagayama $Y$, Eguchi K: Different mechanisms for anti-tumor effects of low- and high-dose cyclophosphamide. Oncol Rep 2006, 16:141-146.

24. Taieb J, Chaput N, Schartz N, Roux S, Novault S, Ménard C, Ghiringhelli $F$, Terme M, Carpentier AF, Darrasse-Jèze G, Lemonnier F, Zitvogel L: Chemoimmunotherapy of tumors: cyclophosphamide synergizes with exosome based vaccines. I Immunol 2006, 176:2722-2729.

25. Ikezawa Y, Nakazawa M, Tamura C, Takahashi K, Minami M, Ikezawa $Z$ : Cyclophosphamide decreases the number, percentage and the function of CD25+ CD4+ regulatory T cells, which suppress induction of contact hypersensitivity. J Dermatol Sci 2005, 39:105-II2. 
26. Nikolin VP, Popova NA, Sebeleva TE, Strunkin DN, Rogachev VA, Semenov DV, Bogachev SS, Yakubov LA, Shurdov MA: Effect of exogenous DNA injection on leukopoietic repair and antitumor action of cyclophosphamide. Vopr Onkol 2006, 52:336-340. In Russian

27. Likhacheva AS, Nikolin VP, Popova NA, Dubatolova TD, Strunkin DN, Rogachev VA, Sebeleva TE, Erofeev IS, Bogachev SS, Yakubov LA, Shurdov MA: Integration of human DNA fragments into the cell genomes of certain tissues from adult mice treated with cytostatic cyclophosphamide in combination with human DNA. Gene Ther Mol Biol 2007, I I: 185-202.

28. North RJ: Cyclophosphamide-facilitated adoptive immunotherapy of an established tumor depends on elimination of tumor-induced suppressor $\mathbf{T}$ cells. J Exp Med 1982, 155:1063-1074.

29. Curiel TJ, Coukos G, Zou L, Alvarez X, Cheng P, Mottram P, Evdemon-Hogan M, Conejo-Garcia JR, Zhang L, Burow M, Zhu Y, Wei S, Kryczek I, Daniel B, Gordon A, Myers L, Lackner A, Disis ML, Knutson KL, Chen L, Zou W: Specific recruitment of regulatory $\mathbf{T}$ cells in ovarian carcinoma fosters immune privilege and predicts reduced survival. Nat Med 2004, 10:942-949.

30. Jordan JT, Sun W, Hussain SF, DeAngulo G, Prabhu SS, Heimberger $A B$ : Preferential migration of regulatory $T$ cells mediated by glioma-secreted chemokines can be blocked with chemotherapy. Cancer Immunol Immunother 2008, 57:|23-131.

31. Polak L, Turk JL: Reversal of immunological tolerance by cyclophosphamide through inhibition of suppressor cell activity. Nature 1974, 249:654-656.

32. Berd D, Mastrangelo MJ: Effect of low dose cyclophosphamide on the immune system of cancer patients: depletion of CD4+, 2H4+ suppressor-inducer T-cells. Cancer Res 1988, 48:167|-1675

33. Weigel BJ, Rodeberg DA, Krieg AM, Blazar BR: CpG oligodeoxynucleotides potentiate the antitumor effects of chemotherapy or tumor resection in an orthotopic murine model of rhabdomyosarcoma. Clin Cancer Res 2003, 9:3 I05-3II4.

34. Obeid M, Tesniere A, Ghiringhelli F, Fimia GM, Apetoh L, Perfettini JL, Castedo M, Mignot G, Panaretakis T, Casares N, Métivier D, Larochette N, van Endert P, Ciccosanti F, Piacentini M, Zitvogel L, Kroemer G: Calreticulin exposure dictates the immunogenicity of cancer cell death. Nat Med 2007, 13:54-61.

35. Obeid M, Panaretakis T, Tesniere A, Joza N, Tufi R, Apetoh L, Ghiringhelli $F$, Zitvogel $L$, Kroemer $G$ : Leveraging the immune system during chemotherapy: moving calreticulin to the cell surface converts apoptotic death from "silent" to immunogenic. Cancer Res 2007, 67:794I-7944.

36. Pratesi G, Petrangolini G, Tortoreto M, Addis A, Belluco S, Rossini A, Selleri S, Rumio C, Menard S, Balsari A: Therapeutic synergism of gemcitabine and CpG-oligodeoxynucleotides in an orthotopic human pancreatic carcinoma xenograft. Cancer Res 2005, 65:6388-6393.

37. Wang XS, Sheng Z, Ruan YB, Guang Y, Yang ML: CpG oligodeoxynucleotides inhibit tumor growth and reverse the immunosuppression caused by the therapy with 5-fluorouracil in murine hepatoma. World J Gastroenterol 2005, I I:1220-1 224.
Publish with Biomed Central and every scientist can read your work free of charge

"BioMed Central will be the most significant development for disseminating the results of biomedical research in our lifetime. "

Sir Paul Nurse, Cancer Research UK

Your research papers will be:

- available free of charge to the entire biomedical community

- peer reviewed and published immediately upon acceptance

- cited in PubMed and archived on PubMed Central

- yours - you keep the copyright
BioMedcentral 